\title{
O Conceito de Tendência na Moda: significado, histórico, conotação
}

- Amanda Queiroz Campos' ${ }^{1}$

- Brigitte Wolf2 


\title{
O Conceito de Tendência na Moda: significado, histórico, conotação
}

\begin{abstract}
RESUMO
Com a intenção de contribuir para o aprofundamento teórico dos estudos de tendência, a presente pesquisa aqui apresentada visa compreender as origens e transformações históricas do termo tendência e, mais especificamente, tendência de moda. Para tal, como procedimento metodológico foi desenvolvida revisão consistente de bibliografia, investigando a etimologia do termo nos idiomas português, inglês e alemão. Além disso, buscou-se agregar diferentes referenciais bibliográficos consolidados nos estudos de tendências - tais quais Caldas, Lindkvist e Vejlgaard - em prol do entendimento e da aplicação das tendências no decorrer do processo histórico. A interpretação geral do conceito de tendência relaciona-se com força ou vetor que direciona a um futuro finito, porém incerto. Entre 1946 e 1975, as tendências adquiriram uma compreensão semelhante à atual, enfatizando sua relevância econômica, o que coincide não arbitrariamente com o nascimento do consumo de massa. A conotação contemporânea associa tendências a mudanças e transformações que envolvem diferentes aspectos socioculturais e econômicos. Já as tendências de moda são compreendidas como expressões das tendências socioculturais em características visuais e táteis de produtos de moda.
\end{abstract}

Palavras-chave: tendência de moda, etimologia, significância.

\section{The Concept of Fashion Trend: meaning, history, connotation}

\begin{abstract}
With the intention of contributing to the theoretical deepening of trend studies, the present research aims to understand the historical origins and transformations of the term trend and, more specifically, the fashion trend. The methodological procedure involved a consistent bibliographical review. Firstly, we investigated the etymology of the term in Portuguese, English, and German. In addition, we combined different consolidated bibliographical references - such as Caldas, Lindkvist, and Vejlgaard - in order to historically understand the concept and its applicability. The general interpretation of the term tendency relates to a force that leads to a finite but uncertain future. Between 1946 and 1975, trends acquired a comprehension similar to their current meaning, emphasizing their economic relevance, which coincides not arbitrarily with the birth of mass consumption. The contemporary connotation associates trends to changes and transformations that involve different sociocultural and economic aspects. In turn, fashion trends are expressions of sociocultural tendencies in visual and tactile characteristics applied to fashion products.
\end{abstract}

Keywords: fashion trend, etymology, significance. 


\section{INTRODUÇÃO}

Os nomes dados aos filhos ${ }^{3}$, o alinhamento a certas teorias científicas, a preferência por caminhonetes $4 X 4$, a recente gourmetização do mundo e as mudanças estéticas que renovam os armários de fashionistas $^{4}$ e pessoas comuns são fenômenos sobre os quais imperou a lógica das tendências. A bibliografia da área insiste em dizer que o significado da palavra tendência foi esvaziado e não é surpreendente perceber que há pouco esclarecimento sobre a definição de tendência, considerando que é algo popular na cultura contemporânea e que afeta indivíduos, empresas e a sociedade em geral (CALDAS, 2015; VEJLGAARD, 2008).

Coloquialmente, tendência é associada às ideias de moda e à novidade, e também às ideias de antecipação e incerteza. Claramente, as tendências são consubstanciais à ideia de moda (MOCHO, 2012). No sentido proposto por Mocho, defendido principalmente por Kawamura (2014) e que direciona o escopo deste trabalho, a moda como sistema atende

\footnotetext{
3 Ver estudo conduzido por LIEBERSON, S. A matter of taste: How names, fashions, and culture change. New Haven: Yale University Press, 2000. e mencionado por GODART, F. Sociologie de la mode. Paris, La Découverte, 2010.

4 De acordo com o Urban Dictionary (2014), fashionista é um termo utilizado para referir-se à mulheres (eventualmente aplicado para homens) devotas a moda e roupas. Essas mulheres teriam "um toque natural para combinar as tendências atuais e vintage de forma moderna". Embora o termo tenha sofrido conotações negativas no passado, a sociedade contemporânea considera um atributo positivo que define as pessoas com entusiasmo pela moda. Veja mais em: http://www.urbandictionary.com/define.php?term=fashionista.
} 
aos conjuntos de produção, desenvolvimento e comunicação de moda. A visão da moda como uma instituição abrange, mais do que as etapas de produção de vestuário e os atores, os estágios onde ocorre o conceito e a prática da moda, como a imprensa de moda, propaganda, branding, criação e varejo.

Nesse contexto, as tendências da moda aparecem amplamente e são consideradas pelos leitores como o conteúdo mais interessante das revistas de moda (BAILEY \& SEOCK, 2010). No entanto, o ethos e o sistema da moda adaptaram a ideia original de uma tendência (mais especificamente, tendência de moda) as suas peculiaridades, envolvendo o conceito nas ideias de volatilidade repetitiva, efemeridade e renovação. Portanto, este trabalho orienta-se pela tarefa de conceituar as tendências principalmente sob o escopo dos estudos de moda.

A língua inglesa apresenta duas palavras diferentes para tendência (trend e tendency), o que não ocorre em outras línguas, como o português e o alemão. A diferenciação geralmente define tendência trend - em relação às ideias de novidade e de moda efêmera, enquanto que o termo tendência - tendency mantém associações com áreas como Estatística e Psicologia, referindo-se a uma inclinação e predisposição de longa data. Por outro lado, o uso de ambas as palavras como equivalentes causa grande parte dos mal-entendidos e do desgaste de conotação quando se trata da compreensão de tais fenômenos.

Embora considerados sinônimos, cada palavra apresenta particularidades e, portanto, associações específicas. A ideia geral que une ambos conceitos implica na significação de direção, extensão e inclinação (COLLINS, 2012). O conceito comum de tendência implica, no entanto, que o vetor ou direção provavelmente será alcançado, compreendendo algo que tende a crescer e tornar-se um padrão. Pelo contrário, uma tendência - mais especificamente uma tendência de moda - raramente será padronizada, pois, como característica do ethos moda, a ampla adoção esvazia o significado simbólico de novidade. 
Da mesma forma como o que ocorre atualmente com o termo design, a palavra tendência foi amplamente utilizada durante os anos 1990 e 2000, sendo forçosamente associada a produtos e serviços como argumento, qualificação ou legitimação. Tal situação, combinada com a lógica da moda rápida (fast fashion), levou a um contexto em que as tendências são muitas vezes percebidas como negativas, referindo-se a meras alterações estéticas, sem qualquer referência ou fundo. Muitas pessoas desfavorecem as tendências, considerando-as seguidas pelas massas, em oposição à expressão da própria individualidade, conforme definido pela busca sem fim de um "novo" com o objetivo de diferenciação social (ESPOSITO, 2014).

As tendências de moda são fenômenos que concernem o gosto e o estilo. Segundo Erner (2012) e Lipovestky (2007), são convergências de desejos e de gesto, caracterizadas por ciclos de variável duração e rápida modificação. Apesar das rápidas renovações responderem diretamente aos interesses da indústria da moda - traduzidas em lucro -, cada tendência envolve duas esferas: [a] esfera cultural arbitrária e [b] uma esfera econômica comercial. Por isso, essa discussão sobre o conceito de tendências considera principalmente o seu sentido ao invés das causas por trás da renovação.

Este artigo consiste em parte dos estudos de doutorado da tese intitulada of tradition and creation: the discourse of fashion designers on trend report usage conduzida sob supervisão dos Professores Doutores Luiz Salomão Ribas Gomez e Brigitte Wolf respectivamente na Universidade Federal de Santa Catarina (Brasil) e na Bergische Universität Wuppertal (Alemanha). O doutoramento em cotutela foi financiado pela FAPESC - Fundação de Amparo à Pesquisa e Inovação do Estado de Santa Catarina -, pela CAPES Coordenação de Aperfeiçoamento de Pessoal de Nível Superior -, e pelo DAAD - Deutscher Akademischer Austauschdienst. Este recorte pretende esclarecer o significado e os atributos do termo tendência e, mais especificamente, dirigir-se ao assunto no âmbito do 
sistema de moda - portanto, tendências de moda. Inicialmente, apresenta-se uma compreensão etimológica do termo, com a intenção de apreender sua origem, antes de compreender a história do seu significado, desde a sua origem até o presente.

\section{PROCEDIMENTOS METODOLÓGICOS}

Este trabalho foi conduzido no campo científico do design, com a justificativa das atividades de design de moda e da relevância dos estudos de tendências (trend studies) para o campo - usualmente nomeado como fashion forecasting ou trend forecasting. Friedman (2003, p. 1) propõe que o campo do design ampliou-se e percorre uma variedade de processos, interfaces e artefatos. Para o pesquisador, conduzir pesquisa em design requer compreender "como as coisas funcionam e porquê", uma vez que geraria análises e a explicações que levam a teorias. Nesse sentido, este artigo contribui para uma compreensão mais aprofundada do fenômeno das tendências, reforçando suas conotações subjacentes, reverberadas através do tempo, e ainda associadas ao conceito.

Igualmente, pode-se justificar esta investigação com apoio em Rech (2013). A professora declara que a pesquisa sobre tendências e suas operações no sistema de moda contribuem "na elaboração de referenciais teóricos de outros campos importantes para o alargamento industrial de países em via de desenvolvimento, como o Brasil" (Ibid., 2013, p. 109100). Sendo assim, investigações de natureza teórica contribuem na aplicação estratégica de tendências, agora compreendidas como mais do que meras alterações formais.

Esta pesquisa tem uma abordagem qualitativa, pois dá prioridade ao aprofundamento da compreensão das conotações e transformações perpassadas pelo termo. A natureza do estudo foi explicativa, já que se tentou entender como as tendências da moda modificaram-se para serem compreendidas da maneira como elas são na configuração atual do sistema de 
moda. Para resolver o problema principal, uma revisão teórica sistemática foi aplicada sob a forma de pesquisa documental. A revisão da literatura incluiu a análise de livros, trabalhos, teses e dissertações sobre temas relacionados a esta pesquisa: o conceito e a história das tendências, mais especificamente das tendências da moda.

\section{ETIMOLOGIA5}

A pesquisa etimológica foi realizada em primeiro lugar na língua portuguesa, uma vez que é a língua nativa da autora e, portanto, a linguagem na qual a maior parte desta pesquisa sobre as tendências da moda foi conduzida. Posteriormente, o artigo apresenta pesquisa etimológica realizada na língua alemã devido à segunda sede do doutorado binacional - e, finalmente, na língua inglesa, que foi o idioma no qual a dissertação final foi escrita. Outras línguas como o francês e o checo contribuíram para a formulação da palavra nas línguas estudadas.

$\mathrm{Na}$ língua portuguesa, a palavra tendência tem o significado de inclinação, propensão, disposição, intenção, movimento e força determinante (BUARQUEDE-HOLLANDA, 1999). A derivação do adjetivo latino tendente criada a partir do verbo tendere formou a palavra tendência (MACHADO, 2003) ${ }^{6}$. Em latim, o vocábulo tendŏ corresponde aos significados de (1) estender-se; (2) apresentar uma oferta; e (3) proceder, prosseguir ou continuar. Em uma conotação figurativa, o termo corresponde às ações de "tender a" e "inclinar-se a" (FARIA, 1962). Tal conotação também se relaciona com uma raiz indo-européia, ten, cujo significado circunda a ideia de alongamento, propensão e tensão (ARTIGUES \& ROBERTS, 1997).

\footnotetext{
5 Etimologia é o estudo da composição e origem das palavras, e de seu significado no decorrer do processo histórico.

6 O verbo em latim, tendere é a origem de diversas palavras portuguesas: tender, tendão, tensor, tensão, tenda, atender, atenção, estender, distender, intento, intendente, pretender. (ERNOUT, A.; MEILLET A; ANDRÉ, J. Dicionnaire étymologique de la langue latine: histoire des mots. Paris: Librairie Klincksieck, 1951.
} 
Em alemão, o vocábulo Tendenz (tendência) é substantivo feminino variante do termo francês tendance, com o significado de direção (Richtung) e predisposição (Neigung). Ele também faz referência ao francês tendre que imprime os significados de estender, alongar, esticar, expandir e prolongar (strecken, dehnen). O vocábulo latino tendere, que corresponde à raiz da palavra em português, reforça a ideia de propagação e estiramento. Comumente, a palavra Tendenz é associada ao vocábulo Streben: anseio, ânsia, esforço para alcançar algo (KÖBLER, 1995).

No idioma inglês, o vocábulo tendency remonta de 1620 e tem origem latina medieval no termo tendentia, variante do termo em latim tendere, cuja elucidação etimológica foi apresentada anteriormente. O termo tendency refere-se ao francês antigo tendre, também variante de raiz latina (COLLINS, 2012). Já o termo trend é mais recorrentemente utilizado na língua inglesa para referenciar a ideia de tendência. Neste caso, a palavra tem referência no vocábulo trendan do inglês antigo, cujo significado satisfaz ao verbo virar; to turn, em inglês. De acordo com Lindkvist (2010), a palavra nórdica-europeia tendr corresponde ao termo, trend, empregado para descrever o curso de rios e correntes marítimas.

De modo resumido, pode-se considerar que o vocábulo agrega as ideias de propensão, inclinação e movimento sugerido ou impulsionado. De modo complementar, a compreensão inglesa e alemã da palavra fornece a ideia de movimento e de algo a ser alcançado, indicando uma condição relacional e sugerindo a existência de um fim (CALDAS, 2015; RAYMOND, 2010). Baseado nesses significados, o conceito semântico de tendência está embasado em três principais pilares: (1) o da alteridade, no sentido que de que a tendência existe mediante a uma força externa que a conduz ou a atrai; (2) o de movimento, emblemático das ideias de inclinação e propensão, e, por fim; (3) o de abrangência, que dá conta dos significados de estender, alargar e desdobrar (CALDAS, 2015). 
Portanto, uma tendência (no sentido geral da palavra) é a inclinação predisposta para algo, alguém ou alguma situação que provavelmente acontecerá no futuro próximo. Tendo uma força atrativa final, a ideia geral de uma tendência é algo que tende a atingir essa alteridade $e$, portanto, tendência apresenta uma sensação de [a] finitude; ou seja, uma situação que será alcançada; e [b] futurologia; isto é, sugerindo que a situação acontecerá no futuro. A relação de tendência com o conceito de propensão também envolve a consideração da incerteza: embora a situação seja susceptível de acontecer, ela ainda não aconteceu, e não há garantia de que seu curso não mudará.

Evidentemente, as ideias associadas ao termo variaram ao longo do tempo, bem como o paradigma científico em voga, e a situação e objetivo em que o termo foi empregado. Para identificar como as conotações e significados originais adquiriram sua configuração atual, realizou-se um estudo bibliográfico histórico, do qual um relatório resumido será apresentado nas páginas a seguir. $O$ objetivo foi elucidar como a primeira conotação do termo, usada como inclinação romântica durante a Idade Média, foi alterada para o significado atual e deu origem a uma vasta gama de termos relacionados, tais como trendy característica daquele que está a par das tendências a trendsetter - influenciador que define e estabelece tendências -, que datam da década de 1960 (COLLINS, 2012; HIGHAM, 2009).

\section{HISTÓRICO}

Historicamente, a primeira aparição da palavra tendência ocorreu na França, cujo registro data da Baixa Idade Média, mais especificamente do século XIII. O termo tinha a conotação de inclinação, todavia, era empregado para sugerir inclinação romântica a outrem (CALDAS, 2015), como manifestação do amor romântico característico da época e da ascensão da burguesia (SANT'ANNA, 2009). A significação reforça o sentido de alteridade, uma vez que requer um 
elemento externo; ou seja, aquele ou aquilo que causa atração, o polo irresistível.

A palavra foi pouco utilizada até o século XVIII, sendo então retomada pelas ciências com o sentido de força em direção específica tendendo para um fim, dinamismo, esforço e impulso. Neste momento durante o século das Luzes, da Revolução Francesa e da Enciclopédia - é que a noção de tendência adquiriu uma de suas principais conotações: a finitude, um movimento que se esgota em si mesmo. Nessa mesma época, a área da Física consolidou o significado do termo, correspondendo à atração e à força, o qual é adotado até os dias atuais por filósofos e cientistas.

Entretanto, a palavra tendência alcançou propagação considerável apenas a partir do século XIX, quando psicólogos passaram a empregá-la na forma plural - tendências - com o sentido de propensão ou predisposição que determinado indivíduo teria de agir de determinada maneira; suas modalidades particulares do desejo; e orientação de suas necessidades individuais. Sob esta prerrogativa, a palavra é acrescida de outra conotação imprescindível para a compreensão que apresenta na contemporaneidade: de uma direção para a qual se aponta, mas que não é necessariamente ou inteiramente atingida (CALDAS, 2015). Essa ideia é central para as associações com a incerteza, as quais são emblemáticas do estudo, pesquisa e adoção de tendências - e, evidentemente, tendências de moda.

É também no século XIX que o vocábulo adquire a conotação evolutiva - que pode causar problemas de ordem teórica - que alguns consideram intrínseca à noção de tendência. Contemporaneamente à Revolução Industrial, ao enriquecimento das potências europeias e ao Positivismo, o sentido de tendência foi contaminado com os juízos de progresso e evolução, sugerindo que a história caminha sobre uma linha reta e direcionada que leva a um devir inexorável (Ibid.). A doutrina positivista defendida por Comte fundamenta o entendimento atual que se tem sobre o conceito de tendência. Pode-se notar a associação na afirmação de William Gibson (2003), que atesta "O 
futuro está aqui, apenas não está uniformemente distribuído", e Florence Müller (2012), que considera que a história das tendências é a evolução das práticas.

Ainda no século XIX, com a emergência da matemática estatística ${ }^{7}$ a palavra tendência foi associada às ideias de movimentos demográficos e observação das massas, altamente aplicada pela sociologia tradicional e às ciências naturais. Durante a maior parte do século $X X$, a palavra tendência foi majoritariamente cunhada por economistas $e$ estatísticos com relação aos resultados de suas pesquisas. Em tais áreas, tendência alude à direção que uma curva toma em um gráfico. Estatísticos comumente usam a palavra tendência quando a direção da curva não é evidente (VEJLGAARD, 2008). De modo pontual, é relevante considerar como as noções de estiramento e alargamento dos resultados significados principalmente utilizados na área de estatística - reverberam a compreensão do termo tendência e a prática de seus estudos.

O primeiro registro que se tem da utilização da palavra tendência para designar um objeto na área do design ocorreu no ano de 1936, nas páginas da revista Trend. A revista foi editada pela DIA - Design and Industrial Association (1915) - associação inglesa com sede em Londres e que tinha objetivos similares aos das Deutschen Werkbunden (1907) alemães: promulgar coesão entre designers, produtores, industriais e revendedores, além de um entendimento mais assertivo do que seria percebido como bom design pelo público consumidor dos itens de design para a casa e para a rotina diária (MONÇORES, 2013a).

Foi entre os anos de 1946 e 1975 que as tendências adquiriram uma compreensão similar à de hoje, enfatizando sua relevância econômica. Sua emergência coincide, não arbitrariamente, com o

7 O escopo das estatísticas aumentou no início do século XIX para incluir a coleta e a análise geral de dados. Hoje, as estatísticas são amplamente aplicadas nas Ciências Naturais e Sociais, incluindo Administração Pública e Privada. Seus fundamentos matemáticos foram apresentados no século XVII com o desenvolvimento da teoria da probabilidade por Pascal e Fermat, e o método dos mínimos quadrados descrito por Carl Friedrich Gauss em cerca de 1790. 
nascimento do consumo de massa, que inaugurou o período intitulado "Os Gloriosos Trinta", em alusão à sua duração. É evidente que os avanços da indústria e a ambição da produtividade ocupam-se de programar lucros a serem renovados continuamente (ERNER, 2012). As tendências adentram a indústria de moda apenas no último terço do século XX. Todavia, desde então, $O$ interesse sobre as tendências é parte indissolúvel do cotidiano das pessoas (VEJLGAARD, 2008).

Os indivíduos estavam ávidos por novidades e o sistema desenvolvido a partir da Revolução Industrial possuía a capacidade de oferecê-las. Com a "inovação" como o principal motor do sistema, o conceito contemporâneo de obsolescência planejada substituiu a destruição criadora que data da década de 1980. As tendências, com foco nas tendências de moda, ocupam lugar central na economia e na sociedade porque solucionam as contradições do capitalismo: produzir sem interrupção um mesmo bem (ERNER, 2012). Desse modo, produzindo quantidades limitadas de determinados produtos em série, a indústria introduz inovações a cada série de produtos, incitando os consumidores à renovarem de seus bens; ou seja, qualquer nova oferta teria a possibilidade de demanda.

A literatura histórica produzida sobre o fenômeno das mudanças constantes - com referência a um período no qual as tendências ainda não haviam sido institucionalizadas, comumente aplicam a terminologia moda - aplicada por Immanuel Kant, por exemplo - ou no plural, modas. Quando se consideram modas, autores tratam especificamente das mudanças ocorridas pelo gosto pela mudança - o que ultrapassa os limites do vestuário, sendo aplicado inclusive em âmbitos considerados tradicionais, como a academia ${ }^{8}$. Pode haver tendências emocionais, intelectuais e até mesmo espirituais, uma vez que tendência é a direção na qual algo tende a mover-se e que surte efeito

8 Ver mais em Svendsen, L. Moda: uma filosofia. Rio de Janeiro: Zahar, 2010. GADAMER, H.G. Verdade e método I: traços fundamentais de uma hermenêutica filosófica., Rio de Janeiro: Editora Vozes, 2005. e SIMMEL, G. Filosofia de la moda. Madrid: Casimiro Libros, 2015. 
consequente na cultura, na sociedade e no setor empresarial em que se desenvolve (RAYMOND, 2010, p.14).

A prospecção de tendências é mais fortemente associada ao setor de vestuário e de acessórios tachado de setor ou indústria da moda - , mas é aplicável em diversos níveis e setores sociais. Isto data do século XIX, e pode ser explicado, dentre outros motivos, pela percepção da velocidade acelerada na qual as mudanças ocorrem no universo das roupas, dos acessórios e dos cabelos. Principalmente a partir da emergência do prêt-à-porter em 1948, a ideia de tendência como renovação perceptível de aspectos estéticos de itens do vestuário surge como resultado da institucionalização das tendências de moda, por meio da criação de um calendário específico para o lançamento das novidades da indústria da moda, desenvolvido pelo Comité de Coordination des Industries de la Mode (Comitê de Coordenação das Indústrias da Moda). A coordenação de moda legitimou-se pela necessidade da organização da produção de acordo com a uma demanda futura.

A partir da década de 1960, a previsão de tendências de moda tornou-se um negócio multimilionário. Empresas como Peclers, Promostyl e Carlin há tempos desfrutam da sua reconhecida e tradicional experiência em proporcionar inspiração futura para designers de moda e para outros trabalhadores criativos. Líder mundial em previsão de tendências, a inglesa WGSN, afirma "definir o que acontecerá amanhã" (WGSN, 2018). Juntamente com a previsão de tendências orientadas à moda, outros profissionais se dedicaram à pesquisa de tendências mais amplas, operando principalmente no nível de consultoria. Alguns deles são: The Future Laboratory, Trend Watching, Kjaer Global, Future Concept Lab, Trend Union, IPSOS, Institute for the future, PSFK, Observatório de Tendências, BOX 1824; entre muitos outros. 


\section{CONOTAÇÃO CONTEMPORÂNEA NO CONTEXTO DA COORDENAÇÃO E PREVISÃO DE TENDÊNCIAS}

Além de Caldas, que trabalha como consultor de tendências, outros analistas de tendências importantes contribuíram amplamente para a definição do termo tendência no campo dos estudos de tendências (trend studies) e suas propostas devem ser consideradas a fim de clarificar as diversas propostas e suas articulações. Os autores cujas contribuições serão consideradas neste tópico são o dinamarquês Henrik Vejlgaard consultor de tendência; o holandês Els Dragt pesquisador independente de tendências; 0 inglês Martin Raymond - do The Future Laboratory; Peter Gloor - do Centro de Inteligência Coletiva do MIT; e William Higham - The Next Big Thing.

Em uma das publicações mais recentes sobre tendências, Els Dragt (2017, p.58) afirma que "não há vocabulário fixo que todos os profissionais de tendências usem". No entanto, existe um terreno comum onde esses pesquisadores do futuro circulam comumente. Para o profissional acima mencionado, a tendência é "uma direção de mudança de valores e necessidades que é impulsionada por forças e se manifesta de várias maneiras dentro de certos grupos da sociedade" (Ibid.). O autor - e muitos outros, como veremos - é claro quanto ao aspecto principal de uma tendência, ou seja, mudança. Para o holandês, para realizar pesquisas de tendências de modo adequado, um investigador deve poder aproximar-se e afastar-se da mudança.

O conhecido pesquisador de tendências e escritor Martin Raymond afirma que "uma tendência pode ser definida como a direção em que algo (qualquer coisa) tende a se mover e que tem consequente efeito na cultura, sociedade ou setor comercial em que se desenvolve" (RAYMOND, 2010, p.14). Para ele, uma tendência também pode ser entendida como uma anomalia. A ideia envolve uma excentricidade, uma incongruência ou uma ruptura na norma. Isto é, as tendências consistem em mudanças. 
Mais especificamente do que Dragt, no entanto, Raymond postula que as tendências consistem na direção tomada pela mudança.

Concordando com os autores previamente citados, o também notório Henrik Vejlgaard considera uma tendência como "um processo social em que o estilo ou o gosto muda" (VEJLGAARD, 2018, s.p.). Da mesma forma que todos os autores revisados para este tópico, o dinamarquês acredita que as tendências são um fenômeno extenso e dizem respeito a vários aspectos da vida cotidiana: dos alimentos à televisão, da forma como nos vestimos à qual nos comportamos. Como alguns autores, Vejlgaard divide diferentes tipologias de tendências (curto e longo prazo). Para ele, e para a maioria, as tendências de moda (fashion changes) geralmente são consideradas fads tendências de duração extremamente curta - porque elas duram somente uma ou duas temporadas (VEJLGAARD, 2008).

Como afirma Gomes (2017, p.5), não se deve esquecer que "uma tendência representa uma mudança de comportamento cultural ou uma mudança de mentalidade que pode ser vista através de pequenas sementes e manifestações de criatividade e inovação nos cenários socioculturais, [sendo uma] forma de gestão cultural". Portanto, apesar de sua duração, todas as tendências têm base cultural e são manifestações de mudanças no comportamento e mentalidade de uma sociedade.

Em uma revisão feita por William Higham no livro intitulado The Next Big Thing, uma tendência pode ser definida como "uma linha de direção ou movimento geral, [...] uma tendência ou inclinação predominante, [...], o movimento geral ao longo do tempo de uma mudança estatisticamente detectável [...] ou um estilo ou preferência atual "(HIGHAM, 2009, p.14-15). O autor, no entanto, considera a definição muito ampla para sua aplicabilidade no marketing mesmo que todas as tendências sejam importantes e possam vir a conduzir o comportamento do consumidor. Para serem consideradas relevantes, elas precisam se relacionar com o ritmo no qual os consumidores mudam seus 
comportamentos. Por essa razão, Higham afirma que as mudanças de curto prazo são inúteis para a estratégia de marketing, sendo razoáveis apenas para aplicações táticas. Assim, para ele "uma tendência é melhor definida como: uma mudança de longo prazo nas atitudes e comportamentos do consumidor que oferece oportunidades de marketing" (HIGHAM, 2009, p.16).

Peter Gloor e o Centro de Inteligência Criativa do MIT (MIT Center for Collective Intelligence) aplicam estudos do futuro sob a denominação de coolhunting. Para eles, existem certos critérios para segregar o que é uma tendência e o que não é - o que é cool e o que não é. Coisas legais (cool) [1] são novas e estimulantes, [2] permitem a participação em uma comunidade e ser bem visto dentro dela, [3] são divertidas e interessantes, e [4] dão sentido à vida das pessoas (GLOOR, KRAUSS e NAAN, 2009, p.1-2).

O campo prático dos estudos do futuro $\mathrm{e}$ prospecção de tendências, por lidar diretamente com o objeto, produziu bibliografia consistente sobre a temática. Dragt e Higham concordam que não há um acerto exato no que é tendência entre os profissionais da área; todavia, traços de correspondência podem ser encontrados - com respaldo em autores teóricos, já revisados nos itens anteriores. Sem sombra de dúvidas, tendência é mudança. De modo mais exato, a tendência é a direção para qual uma mudança aponta. Teóricos e práticos concordam que as tendências se manifestam amplamente e influenciam várias esferas sociais e culturais, com impacto em esferas política e econômica. Sob viés econômico, estudiosos de marketing consideram válidas aquelas tendências que têm impacto no comportamento do consumidor. Tais tendências podem ser aplicadas taticamente ou estrategicamente, dependendo da tipologia da tendência em questão. 


\section{CONCLUSÃO}

A apresentação da etimologia e história do termo teve como objetivo clarificar o conceito de tendência e como ele foi sendo remodelado pelos diferentes momentos históricos e paradigmas científicos. A partir de várias fontes, o conceito geral da palavra tendência absorveu o significado de força ou vetor que leva a um futuro finito, o qual é seu objetivo, mas cujo alcance é incerto. Mais especificamente relevante para o presente estudo, a conotação contemporânea da tendência coincide com três principais fatores históricos e econômicos: [1] o florescer de um ethos moda e o surgimento da burguesia na Baixa Idade Média, que valorizou a mudança, a novidade e a renovação; [2] a produção em massa no início do século $X X$, após a Revolução Industrial; e [3] a possibilidade de acesso a bens de consumo para uma grande parte da população. Em relação à dinâmica do mercado, o conceito atualmente envolve novidades estéticas adotadas principalmente por produtos que a população consumirá no futuro, servindo como ferramentas da coordenação entre oferta e demanda. No entanto, as tendências não são necessariamente tendências de moda e nem sempre envolvem interesse econômico. Como estratégias de mercado, as tendências também se referem a um contexto sociocultural, mesmo nos casos em que a explicação sociocultural da tendência esteja por detrás do desejo e da recorrência da mudança (SVENDSEN, 2010). De acordo com a literatura acadêmica revisada, é possível afirmar que as tendências consistem em mudanças. São transformações que envolvem diferentes aspectos das esferas social, cultural, individual e estética. Tais transformações são aceitas como positivas devido à lógica da ordenação, renovação e normalização da mudança fundamentada no ethos moda. As tendências podem ser mudanças autolegitimadas, mas elas concordam em maior ou menor grau com o espírito do tempo - Zeitgeist. As tendências de moda são expressões de tendências que são fundamentadas socioculturalmente - em 
âmbitos estéticas, principalmente por meio de características visuais e táteis aplicadas aos produtos de vestuário e acessórios e muitas vezes são consideradas fads ou tendências de curto prazo. Estas tendências momentâneas são de aplicabilidade tática, enquanto as tendências de longo prazo, mais duradouras, são adequadas para prática estratégica.

\section{Referências}

ARTIGUES, Bárbara Pastor; ROBERTS, Edward. Diccionario Etimológico Indoeuropeo De La Lengua EAspañola. Madrid: Alianza Editorial, 1997.

BAILEY, Lauren R.; SEOCK, Yoo-Kyoung. The relationships of fashion leadership, fashion magazine content and loyalty tendency. Journal of Fashion Markteing and Management, v.14, n.1, p. 39-57. 2010. Disponível em: http://www.emeraldinsight.com/doi/abs/10.1108/13612021011025429 BUARQUE DE HOLANDA, Aurélio. Novo Dicionário Aurélio. Rio de Janeiro: Editora Nova Fonte, 1999.

CALDAS, Dario. Observatório de Sinais: teoria e prática da pesquisa de tendências. ed. at. São Paulo: Editora SENAC SP, 2015.

COLLINS, Harper. Collins English Dictionary Complete \& Unabridged. Digital edition. Glasgow: Harper Collins Publishers, 2012.

DRAGT, Els. How to Research Trends: use trend watching to boost innovation. Amsterdam: BIS Publishers, 2017.

ERNER, Guillaume. Sociología de Las Tendencias. $1^{a}$ ed. $2^{\mathrm{a}}$ reimp. Barcelona: Editorial Gustavo Gili, 2012.

ESPOSITO, Elena. Originalität durch Nachahmung. pp.198209. apud: LEHNERT, Gertrud; KÜHL, Alicia; WEISE, Katja. (Hg.). Modetheorie: klassische texte aus vier jahrhunderten. Fashion Studies. Bielefeld: transcript Verlag, 2014. 
FARIA, Ernesto (org.) Dicionário Escolar Latino-

Português. 3a ed. Brasília: Ministério da Educação, 1962.

Disponível em:

http://www.dominiopublico.gov.br/download/texto/me001612.pdf.

Acesso em: 15 mai. 2014.

FRIEDMAN, Ken. Theory construction in design research: criteria: approaches, and methods. Design Studies, v.24, n.6, p. 507-522, nov. 2003. Disponível em https://www.sciencedirect.com/science/article/pii/S0142694X0300039 $\underline{5}$

GIBSON, Willon. The Economist [entrevista]. 4 de dezembro de 2003. Disponível em:

https://pt.wikiquote.org/wiki/William Gibson

GLOOR, Peter, KRAUSS, Jonas, NAAN, Stefan. Coolfarming: how cool people create cool trends (Online). Disponível em: http://www.ickn.org/documents/edumedia09 coolfarming.pdf. Acesso em 17 jan. 2018.

GOMES, Nelson Pinheiro. The management of culture:

professional challenges of managing narratives and brands in a changing cultural environment. e-Revista LOGO. v.6 n.1, p.1-19, abr. 2017. Disponível em:

http://incubadora.periodicos.ufsc.br/index.php/eRevistaLOGO/article/v iew/4526

HIGHAM, William. The Next Big Thing. London: Kogan Page, 2009.

KÖBLER, Gerhard. Deutsches Etymologisches

Wörterbuch. Derwbhin: Wassertrüdingen, 1995.

LINDKVIST, Magnus. O Guia do Caçador de Tendências: como identificar as forças invisíveis que moldam os negócios, a sociedade e a vida. São Paulo: Editora Gente, 2010.

LIPOVETSKY, Gilles. O Império do Efêmero: a moda e seu destino nas sociedades modernas . $10^{a}$ reimp. São Paulo: Companhia das Letras, 2007.

MACHADO, José Pedro. Dicionário Onomástico

Etimológico da Língua Portuguesa. Lisboa: Livros Horizonte, 2003.

MOCHO, Jean Pierre. Editó. p.3. In: BACRIE, Lydia. (ed.) Qu'est-ce Qu'une Tendance de Mode? Paris: Fédération Française du Prêt à Porter Féminin, 2012.

MONÇORES, Aline. Tendências: o novo constante. 2013. 177f. Tese (Doutorado). Programa de Pós-Graduação em Design Departamento de Artes e Design da Pontifícia Universidade Católica do Rio de Janeiro, Rio de Janeiro, 2013.

MÜLLER, Florence. Tendances et innovations. pp.16-27. In: BACRIE, Lydia. (ed.) Qu'est-ce Qu'une Tendance de Mode? Paris: Fédération Française du Prêt à Porter Féminin, 2012.

RAYMOND, M. Tendencias: que son, cómo identificarlas, en qué fijarnos, cómo leerlas. London: Promopress, 2010. 
RECH, Sandra Regina. Estudos do Futuro \& Moda: uma abordagem conceitual. ModaPalavra e-Periódico. v.6, n.11, p.93-100. jul-dez 2013. Disponível em:

http://www.revistas.udesc.br/index.php/modapalavra/article/view/3477 16851

SANT'ANNA, Mara Rúbia. Teoria da moda: sociedade, imagem e consumo. $2^{a}$ ed. Barueri, SP: Estação das Letras, 2009.

SVENDSEN, Lars. Filosofia da Moda. Rio de Janeiro: Zahar, 2011.

VEJLGAARD, Henrik. Anatomy of a Trend. New York:

McGraw-Hill, 2008.

VEJLGAARD, Henrik. Trend Forecasting: understanding trends. 2018. Disponível em:

http://www.henrikveilgaard.com/?id=161\#question11. Acesso em 17 jan. 2018. 